\title{
IMAGE-BASED VIRTUAL TOURS AND 3D MODELING OF PAST AND CURRENT AGES FOR THE ENHANCEMENT OF ARCHAEOLOGICAL PARKS: THE VISUALVERSILIA 3D PROJECT
}

\author{
C. Castagnetti ${ }^{\mathrm{a}^{*}}$, M. Giannini ${ }^{\mathrm{a}}$, R. Rivola ${ }^{\mathrm{b}}$ \\ ${ }^{a}$ DIEF Geomatics Section, University of Modena and Reggio Emilia, Via Vivarelli 10, 41125 Modena, Italy - (cristina.castagnetti, \\ martina.giannini)@unimore.it \\ ${ }^{\mathrm{b}}$ GEIS - Geomatics Engineering Innovative Solutions Srl, Via Vivarelli 2, 41125 Modena (Italy) - \\ riccardo@geomaticsengineering.it
}

KEY WORDS: Terrestrial laser scanning, 3D Surveying, 3D Modeling, Spherical images, Virtual tours, Archaeology, Versilia (IT)

\begin{abstract}
:
The research project VisualVersilia $3 D$ aims at offering a new way to promote the territory and its heritage by matching the traditional reading of the document and the potential use of modern communication technologies for the cultural tourism. Recently, the research on the use of new technologies applied to cultural heritage have turned their attention mainly to technologies to reconstruct and narrate the complexity of the territory and its heritage, including 3D scanning, 3D printing and augmented reality. Some museums and archaeological sites already exploit the potential of digital tools to preserve and spread their heritage but interactive services involving tourists in an immersive and more modern experience are still rare. The innovation of the project consists in the development of a methodology for documenting current and past historical ages and integrating their 3D visualizations with rendering capable of returning an immersive virtual reality for a successful enhancement of the heritage. The project implements the methodology in the archaeological complex of Massaciuccoli, one of the best preserved roman site of the Versilia Area (Tuscany, Italy). The activities of the project briefly consist in developing: 1. the virtual tour of the site in its current configuration on the basis of spherical images then enhanced by texts, graphics and audio guides in order to enable both an immersive and remote tourist experience; 2. 3D reconstruction of the evidences and buildings in their current condition for documentation and conservation purposes on the basis of a complete metric survey carried out through laser scanning; 3. 3D virtual reconstructions through the main historical periods on the basis of historical investigation and the analysis of data acquired.
\end{abstract}

\section{INTRODUCTION}

The documentation of the cultural heritage through digital archiving in the recent past has become a global goal, and at the same time a challenge to ensure the transmission to future generations (National Library of Australia, 2003). Cultural heritage and technologies are today strongly linked: the modern technologies related to geomatics and information technology offer significant potential applications for the documentation, the representation, the fruition and the multimedia communication of cultural heritage (Böhler et al., 2001). In recent years the studies regarding the use of new technologies applied to cultural heritage have turned their attention mainly to technologies suited to reconstruct and narrate the complexity of the territory and cultural heritage, including 3D modeling and augmented reality (Noh et al., 2009; D'Agnano et al., 2015), which, as the name implies, allow the user to enrich the reality through the visualization of digital graphic contents overlapped to the real vision of what he/she is seeing (Fritz et al., 2005).

The use of 3D survey technology applied to the study of historical buildings is, indeed, become an established method for determining the geometry of the structures, because it provides comprehensive and accurate analysis even in complex architectures (Guarneri et al., 2004; Neubauer et al., 2005; Castagnetti et al., 2012; Capra et al., 2015; Tucci et al., 2016), allowing the perception of geometrical details difficult to be detected with traditional techniques. The result is a $3 \mathrm{D}$ database that is helpful for improving the knowledge and for the design of any intervention aimed at conservation. Thanks to the interaction with computer techniques for visualization and online dissemination (Guarneri et al., 2010; Meyer et al. 2002;
Tucci et al., 2010; Tucci et al., 2011; Balletti et al., 2015; Rivola et al., 2016), the surveying technologies, and particularly laser scanning and photogrammetry, can be used effectively for more purposes than exclusively technical ones. However, such use is not always accompanied by a full awareness of the value and potential of three-dimensional products such as communication tools for study and research, addressed as much to the public of the experts as to a larger user (Orlandi et al., 2014).

Many museums and archaeological sites already use the potential of digital technologies to preserve and promote their heritage. For example the British Museum and the Louvre Museum allow to remotely visit their halls; moreover, the Google Art Project (www.googleartproject.com) makes it possible to view the collections of several museums around the world. The open source software Google Earth (Bassani et al., 2013), as well as being an important tool for the study of geography, also enables the study of the history of Rome by traveling through time to discover the ancient city with threedimensional reproductions of the main buildings.

VisualVersilia $3 D$ is a research project that accepts the challenge to employ the modern technologies of 3D surveying and modeling for stimulating tourism by enhancing the heritage of a territory. Thanks to a specific case study, the paper describes the major results obtained by the project and shows the potentialities of innovation for the cultural heritage of the new millennium. The final goal is the development of a methodology for modeling multiple historical periods and integrating these three-dimensional visualizations. The methodology delivers a prototype that enables the user to 
navigate in an immersive virtual reality. In this way, a visit to the archaeological park will become a complete experience that is different from what is possible with only traditional paper guides and able to adjust the information to the desires and the needs of the users by providing personalized and georeferenced information in real time, namely strictly related to the spaces visited.

\section{THE PROJECT}

Recently, public and private entities have turned their attention to the protection, enhancement and dissemination of the heritage of Versilia (Figure 1): some examples are the creation of the website Terre di Lucca and Versilia (www.luccaterre.it), promoted by the Province of Lucca, the many scientific publications produced by scholars or the archaeological excavations carried out to improve the knowledge of the past in the territory. All these examples are based on a traditional approach and traditional tools. To date, indeed, the cultural heritage of Versilia was not considered as a whole and has not been studied by relating it to the changes of the landscape; there are no products able to tell and show the area's history and cultural heritage through the use of advanced technologies, and particularly through the use of navigable 3D reconstructions.

VisualVersilia $3 D$ is a research project that aims at introducing innovation in the way to exploit and enhance a territory together with its heritage. The background lies in a previous research project, named VisualVersilia, that during the last three years led to the realization of a WebGIS (Web Geographic Information System). The VisualVersilia WebGIS is a sort of digital guide able to map, to tell about and to visualize all the cultural heritage major sites of Versilia (Giannini, 2016; Dubbini et al., 2016). It is also able to show the changes undergone over time by contextualizing the cultural sites within the reconstructions of territorial transformations referable to the various historical periods. Moreover, the VisualVersilia $3 D$ research project aims to enrich the content of the existing WebGIS with virtual tours and 3D navigable reconstructions of past and current appearances. Particularly, the innovation for the local context lies in the multi-temporal domain and in the possibility to virtually envisage the current and past epochs of a specific site. The studies, excavations and surveys conducted over time on the Massaciuccoli archaeological site have therefore created the ideal conditions to try to further enhance a site already well documented and rich in history.

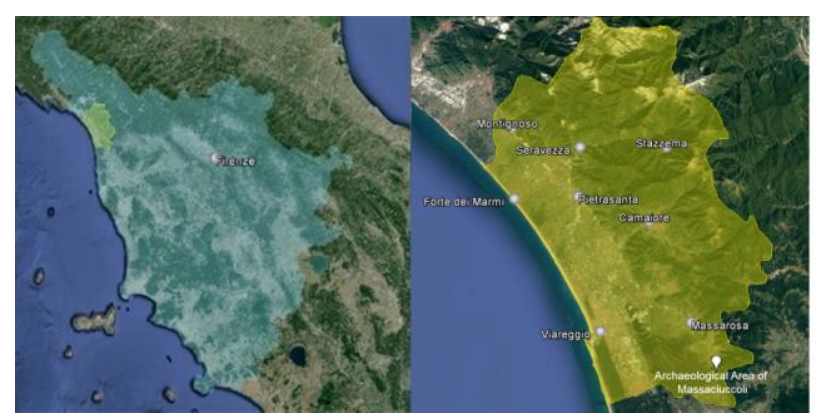

Figure 1. Location map of Versilia, the sub-region of Tuscany Italy (left) where the research projects, named VisualVersilia and VisualVersilia 3D, were developed. A focus of Versilia territory with main towns (right).

The aim of this research, therefore, has been to rebuild the stratification and the evolution of a segment of a territory, starting with the current configuration of the site and going back to the construction of the villa in the early years of the $1^{\text {st }}$ century A.D. and to the subsequent developments during the Roman era. The complete 3D survey of the site allowed the creation of an accurate three-dimensional reconstruction of the current state of conservation of places and buildings for documentation and conservation purposes, making it possible to formulate hypotheses about the reconstruction of the Roman era structures and of the articulation of the thermal baths. The modeling related to the ancient period is the result of reconstructive hypothesis thanks to the continuous comparison of the accurate metrical data provided by the survey with historical sources and with previous bibliography. The metric accuracy of the measurements has indeed imposed an equally rigorous architectural interpretation of the structures and their functions able to justify the collected data.

\subsection{The case study}

The archaeological area of Massaciuccoli (Massarosa, Lucca Province) is located in Versilia (Italy), a sub-region of NorthWestern Tuscany (Figure 1). The area surrounding the lake of Massaciuccoli, which in antiquity had to appear as a vast coastal lagoon, has shown evidence of human presence since prehistoric times. Between the Archaic and Hellenistic periods, the lagoon was occupied by Etruscan settlements with commercial functions. This function continued in Roman times, when the area was reclaimed and it was one of the landing points on the coast of Versilia. On the first slopes of Mount Aquilata and approximately on the bank of the Eastern shore of Massaciuccoli Lake, there are the ruins of two big complexes from the imperial Roman era, concerning a luxurious villa (Ciampoltrini, 1994; Ciampoltrini, 1998; Ciampoltrini, 2009; Giannini, 2015) and another structure recently investigated and located along the ancient road network, which connected the three important sites of Pisa, Lucca and Luni. This structure was profoundly transformed with a succession of interventions begun during half of the $1^{\text {st }}$ century A.D. and concluded by the first half of the $2^{\text {nd }}$ century A.D.: it evolved from an agricultural facility to villa/mansio (Paribeni, 2012), or both, and other spaces were added to fulfil the needs of reception, of stay and refreshment for travellers.

The first mention of the villa, focus of this research, dates back to a document of 874 , in which a wall «que dicitur antiquus» was mentioned. During the excavations of 1770 a lead pipe signed by L. Venuleius Montanus et L. Venuleius Apronianus (CIL; Minto, 1921; Targioni Tozzetti, 1768-1779; Arrighi, 1963; Fabiani, 2006) was recovered, which made it possible to attribute the villa to the Venulei family, the owners of lands and pottery factories in the Pisan territory (Ciampoltrini, 1994; Fabiani, 2006 pp.59; Ciampoltrini, 2009; Paribeni, 2012). The archaeological essays and studies conducted over time on the hill of the parish church of San Lorenzo allowed us to recognize two rooms: one with coloured marble flooring of various shapes and sizes (opus sectile), the other with a mosaic floor in black and white tesserae, of a rich otium $^{1}$ suburban villa, built on the shores of the lake during the early decades of the $1^{\text {st }}$ century A.D. and later restored several times during the first two centuries of the empire (Ciampoltrini, 1994; Ciampoltrini, 2009). These rooms had to belong to the residential quarters built on the wide terrace on which then rose the early Christian church, while initially a garden surrounded by a wall with

${ }^{1}$ In ancient Roman times the otium villas were built outside the city in the countryside or along the coast as home setting that evoked peace, leisure, simplicity and serenity, contrasted to the busy city life with all the businesses (negotium). 
towers was on the lower terrace. Later, during the renovation of Neronian and Flavian times, around the second half of the $1^{\text {st }}$ century A.D., the garden was sacrificed to build thermal and living rooms, which, in the $2^{\text {nd }}$ century A.D., were merged into a single and articulated thermal area (Figure 2), characterized by rich architectural decorations and polychrome marbles. The bath complex was therefore part of a system of banqueting and resting spaces, and probably it had to be structured as follows (Ciampoltrini, 2009) and as shown in Figure 2: one of the stairs (D) which connected the two terraces led to two rooms (A and B) with probable function of reception or representation and to the hypothetical independent entrances to the baths complex. Through a vestibule (E) it was possible to access at the heart of the villa, a quadrangular room $(\mathrm{H})$ with a esedra with a tub (L) and with another bathtub on which cascading water fell (I), i.e. the triclinium-nymphaeum used for banquets. Afterwards this room was probably converted into a frigidarium with a bathtub with cold water (I), and at the same time perhaps the esedra became a tub with hot water, as suggested by the room with a boiler and large oven (praefurnium) on the back (R). In this area there were various service spaces, which could also be reached through other stairs $(\mathrm{P})$ : the latrine $(\mathrm{Q})$ and the corridor (N). From the triclinium-nympheum it was possible to go to the original thermal area, the hypothetical room where they undressed, the apodyterium (X), a now disappeared corridor or passage probably allowed them to reach the room with a more moderate temperature, the tepidarium $(\mathrm{T})$, and then the caldarium (S), a space with a hot temperature and a tub of hot water. Next to the room where they undressed there was a well heated room used for rest or refreshment during the coldest periods (Y). Another significant space of the complex was a wide sudatio $(\mathrm{Z})$, i.e. a sauna, with a central basin containing hot water heated by an oven placed under the marble floor. In the centre of the floor there was a lead plate which further helped to raise the temperature of the room; the area was also heated thanks to a heating system called hypocaust, powered by an oven, the praefurnium, placed probably between $\mathrm{V}$ and $\mathrm{Z}$. The hot air was circulating in the empty space under the floor, which was suspended through the use of brick pillars, and also inside the walls through a cavity specially created. Some corridors (U and V) and service facilities with vaulted ceilings, allowed the servants to power the heating system without being seen.

The otium villa of Massaciuccoli, therefore, surrounded by greenery, richly decorated, fitted with thermal baths, with a picturesque view and inserted in the main routes, attests to the tourist value of Versilia, which dates back from 1800, and characterizes more and more this area ${ }^{2}$.

\footnotetext{
${ }^{2}$ For example the Roman villa of Bocca di Magra was built from the middle of the first century B.C. in Lunigiana, a land between Tuscany and Liguria, when the bay of the Gulf was much deeper and the mouth of Magra river was located a few miles upstream. The building was built in fact as a panoramic villa, with a complex architecture and rooms arranged in terraces down to the sea, which adapt to the rocky nature of the slope and the cliffs below, today buried. From the documents it is possible that at that time there were several similar villas, located in suggestive and sought after positions, ideal for the leisure of Roman aristocrats (Ciampoltrini, 1994, pp. 119).
}

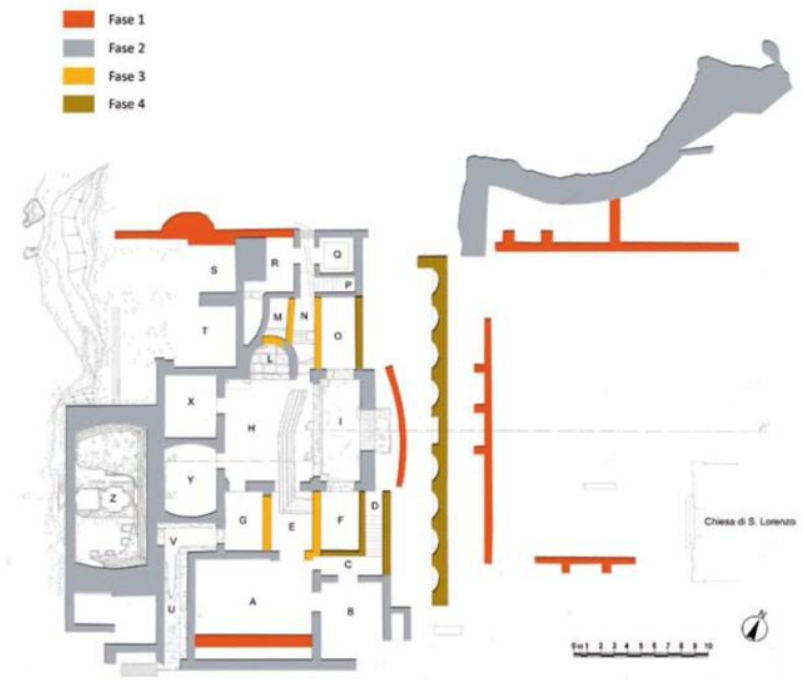

Figure 2. The thermal area of the otium sub-urban villa in the Massaciuccoli archaeological park (North-Western Tuscany, Italy), part of a system of banqueting and resting spaces.

\section{THE TECHNOLOGIES}

\subsection{The survey}

The three dimensional survey focused on the thermal area of Massaciuccoli archaeological park and was carried out by means of laser scanning technology, able to provide a comprehensive point cloud to describe the geometry and the current state of conservation of the structures as well as the surrounding environment. The survey was performed in September 2016 with a time-of-flight terrestrial laser scanner, model ScanStation C10 by Leica Geosystems (hds.leicageosystems.com), which is ideal for architectural survey applications also considering the ability to ensure the coherence of vertical components thanks to the internal dual-axis compensator. The survey consisted of 30 scans, provided by as much scanning positions (top Figure 3), for a duration shorter than two working days. The choice of the spatial resolution was weighted by evaluating the purpose of the survey, being an accurate documentation that could lead to the traditional twodimensional tables at a representation scale of 1:100, and the risk of obtaining an unnecessary redundant final point cloud, resulting in an excessively high computational burden during data processing. The resolution was finally set at $5 \div 8 \mathrm{~mm}$ depending on the distance to the surveyed portion so to guarantee a full and comprehensive point cloud.

As soon as the scanner finished the data collection, $360^{\circ}$ photographic acquisitions with HDR (High Dyinamic Range) mode were performed from each scanning locations. The image collection was performed via an external camera, model Canon EOS $5 D$ mark II with calibrated $35 \mathrm{~mm}$ lens, in order to provide high quality spherical images with double purpose: first the panoramas are coupled to the point cloud obtained from the same location so to enrich with the photo-realistic appearance (central Figure 3); secondly the panoramas are then used for producing the virtual tour of the site. For each scanning position, the image collection consisted in capturing 60 photos at three different exposures, for a total amount of 180 photos.

\subsection{The data processing}

The laser scanning data processing consists in removing the parts which are not of interest, in filtering the noise in the 
dataset and mainly in aligning each scan performed from the scheduled scanning locations. The alignment process combines all the point clouds into the same coordinate system, thus providing the overall $3 \mathrm{D}$ point cloud model of the investigated site (central Figure 3). The alignment was carried out by means of the manual identification of homologous points to be recognized within multiple scans, then the surface matching allows to refine the process and improve the quality of combination. The surface matching is based on the Iterative Closest Point (ICP) algorithm (Besl and McKay, 1992; Chen and Medioni, 1992; Zhang, 1994) and allowed to obtain a subcentimeter average error of $7 \mathrm{~mm}$ in the final alignment process. The laser scanning data processing was performed by the software Cyclone v.9.1 by Leica Geosystems (hds.leicageosystems.com). For each scanning position, the HDR spherical panorama was created by combining and stitching all the collected images; the procedure was carried out with the software PT Gui v.10.0 (www.ptgui.com) that provided very high quality results (Figure 4).
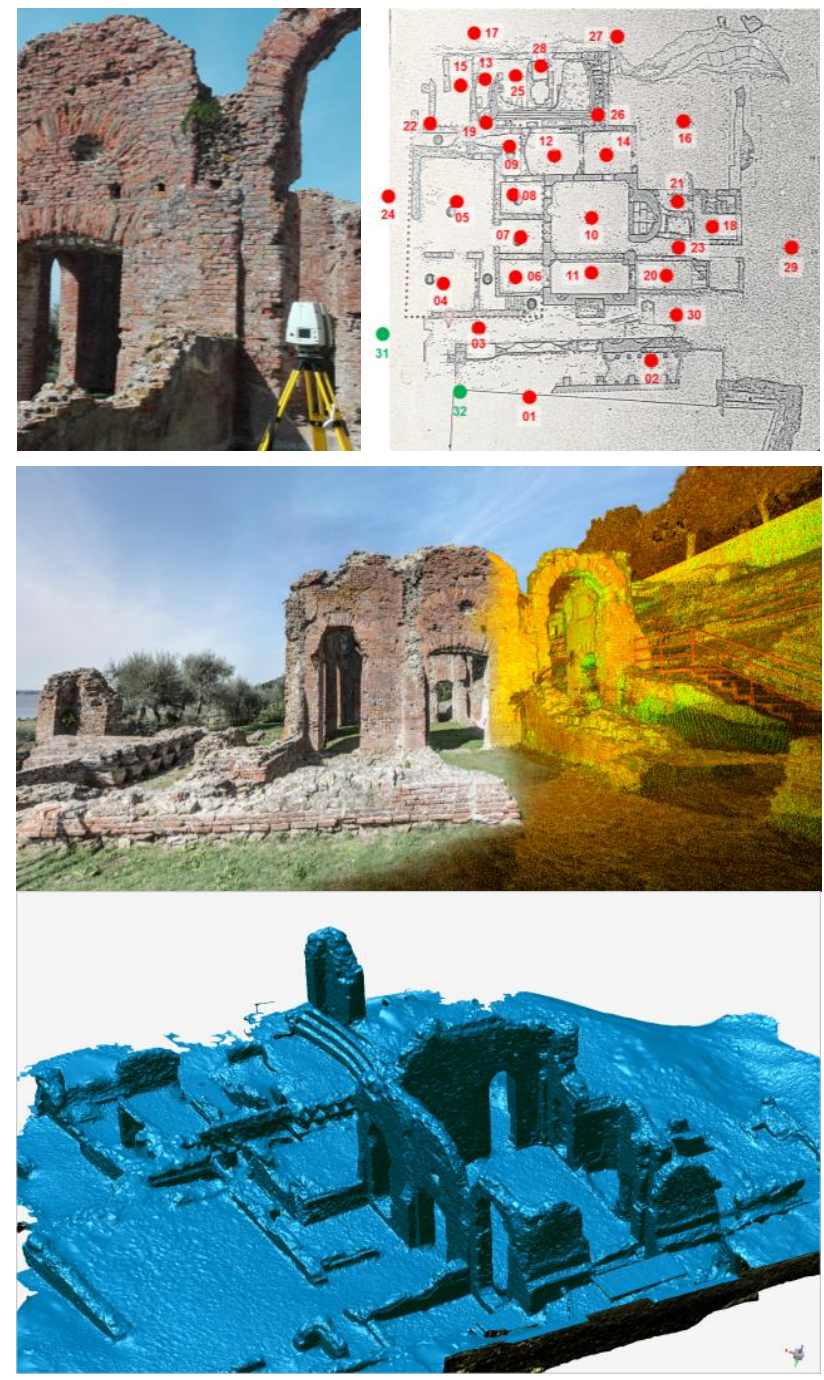

Figure 3. Laser scanning survey of the thermal area of Massaciuccoli archaeological park. From top to bottom pictures: the instrument, model ScanStation C10 by Leica Geosystems during scanning activities (top left) and planning of the scanning positions (top right); 3D point cloud with intensity

false colors (central right) and photo-realistic appearance (central left); 3D model obtained by meshing process.

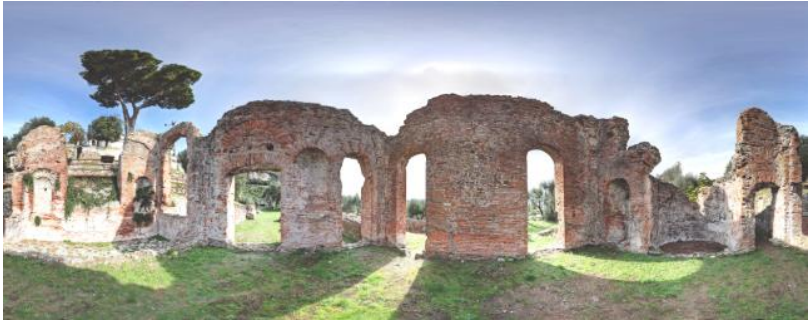

Figure 4. Spherical panorama of the thermal area, the frigidarium (H, I, L in Figure 2). The high quality is obtained by using an external camera, Canon EOS 5D mark II.

\section{THE PRODUCTS}

\subsection{The virtual tour}

The spherical panoramas were then used to create an imagebased virtual tour of the site that allows any tourist to remotely visit and appreciate the site, thus enabling and stimulating the real on site tourism. The attraction comes from an online interactive tour that allows to freely move within the site and to click on whatever interesting button. The tour is produced by the software Easypano Tourweaver v.7.98 (www.easypano.com) that briefly consists of importing the panoramas, creating a suggested path and still allowing a free navigation, inserting hotspots and adding link for accessing to many kind of multimedia contents such as videos, audio files, pictures, documents, external links and so on. The look of the tour is fully customizable and finally provides a link that can be included within any existing website; in this research project the tour will be integrated in the VisualVersilia WebGIS.

This research was, therefore, carried out using a multi and interdisciplinary approach, through the work of archaeologists, geographers, computer scientists, historians and experts in geomatics engineering. The first prototype of virtual tour resulting from the case study (Figure 5), indeed, allows the user to interactively navigate within the various rooms, to remotely explore the site in its current appearance such as it would be actually there, to listen audio descriptions of what is visualized as well as to read supplementary worksheets thanks to in-depth information buttons, as provided by the various scientists involved. The development of the project will lead to create a virtual tour of past ages in order to virtually immerse the tourist in the past appearance of the archaeological site by means of the 3D modeling of ancient structures and the territorial reconstructions studied during the previous research project, VisualVersilia.

\subsection{The past age in 3D}

In recent years, computer graphics and information technologies strongly facilitated the exploitation of the products obtained by 3D surveys for tourist and educational purposes as well as for cultural heritage enhancement and sharing. However, in order to assure the usability of 3D models and 3D dataset by users, for example via web from home, further efforts are required. Such an effort has been required to manage the case study point cloud and provide an easy to display and navigate $3 \mathrm{D}$ model of past ages. Both the technical expertise in $3 \mathrm{D}$ modeling and the historical knowledge about the way structures were built in the past are essential to provide a good final 3D reconstruction. Documentation and hypothesis about the past appearance of the thermal site are partially described in section 2.1 and are still in progress. 


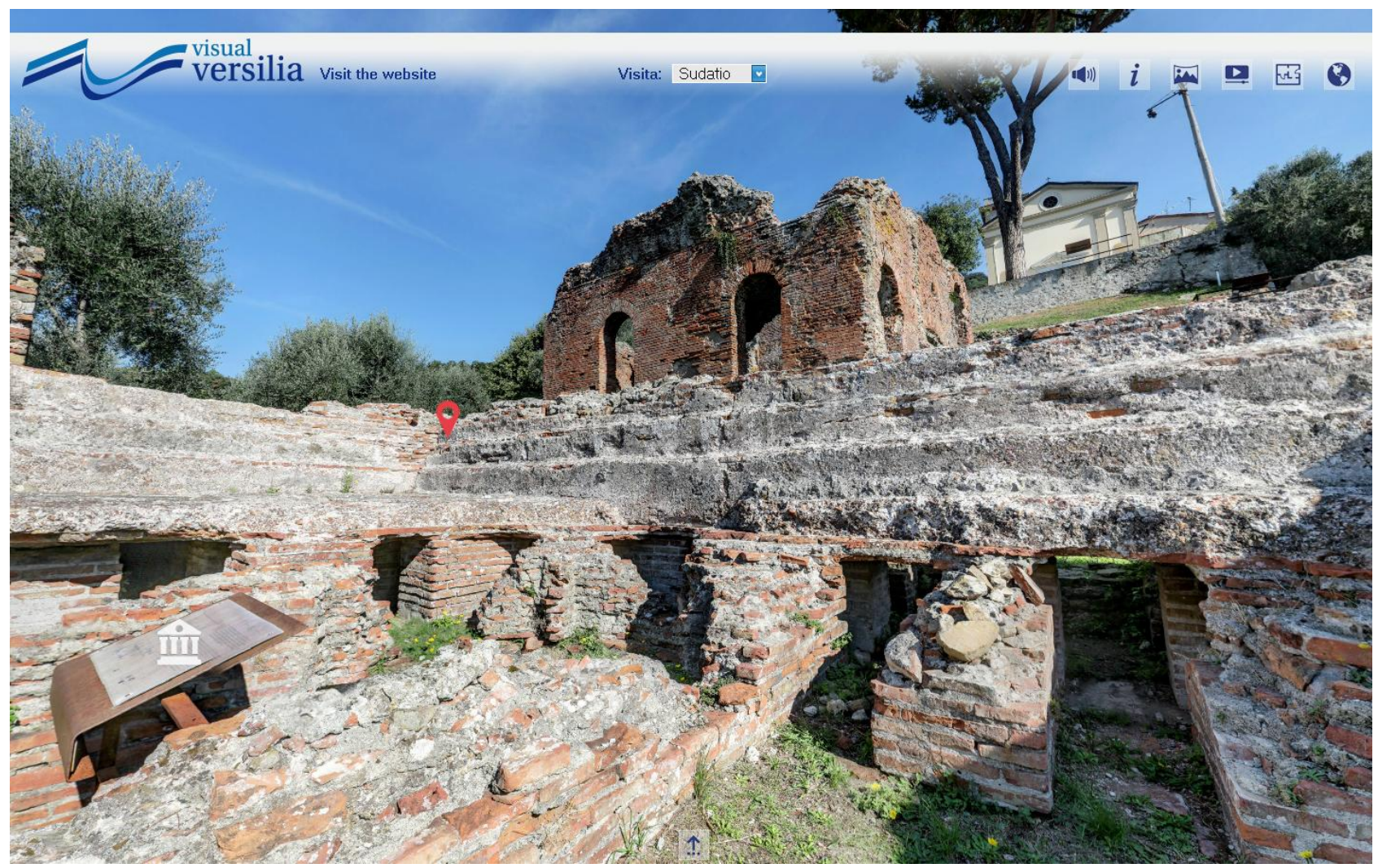

Figure 5. Web view of the virtual tour, sudatio ( $\mathrm{Z}$ in Figure 2) - thermal area of Massaciuccoli archaeological site: the tourist can interactively navigate through the various rooms and immerse within the current appearance of the site. Red hotspots identifies next point of interest and other symbols (the white temple) highlights link to supplementary information.

Concerning the 3D modeling, primarily the point clouds have been processed through the software Geomagic Studio (www.geomagic.com) for creating and managing the meshes. Secondly, the software Rhinoceros v.5 (www.rhino3d.com) has been used to proceed to the geometric surface modeling by accurately following the geometric information of the current remains (given by the 3D mesh model provided by laser scanning survey) and produce the precise 3D reconstruction of the thermal area (Figure 6), as appeared in the past age. This activity is still in progress: although simple geometric primitives have been used, the modeling activity is following a rigorous scientific approach that combines the solid acquired metric information and philological conjectures, in order to create an emotional but truthfully $3 \mathrm{D}$ reconstruction.

\section{CONCLUSIONS}

Today, computer graphic technology is used in a widespread manner to enrich the communication of information in exhibitions, museums and cultural sites in general. The acquisition and processing of metric data collected by scanning techniques and / or photogrammetry paves the way for an interesting use, the virtual reconstruction, that represents a challenging research topic in the conservation field of applications by allowing the study of the degradation, of the lacks and their virtual integration. The paper describes the work in progress of a research project, VisualVersilia $3 D$, that represents an innovation in the way to stimulate and promote tourism in this sub-region of Tuscany (Italy). The challenge to attract tourists by focusing on the cultural and natural heritage is pursued by combining the use of advance technologies for 3D surveying and modeling with in-depth studies of the history and the undergone modifications of the territory. All these aspects lead to a general improvement of information and to a growth of research as well as archaeological and architectural representation. The project delivers an image-based virtual tour of a valuable case study, the thermal area of Massaciuccoli archaeological park, with the aim to show a prototype that is easily reproducible in further sites. The tour virtually allows a tourist to visit and appreciate the current state of conservation of the park. On the basis of the laser scanning survey, the 3D modeling of the past ages is in progress with the purpose to deliver more virtual interactive tours where the tourist immerse himself into the past appearance of the site. The interlocutor of VisualVersilia $3 D$ is a wide and varied audience consisting of citizens, students, tourists and technicians of the territory. In fact, the contents have been created to be diversified and stratified in relation to different requirements of the users. The multi-level knowledge will be able to promote greater awareness of the cultural heritage, which will result in the preservation and enhancement of the testimonies of the history of the area.

\section{ACKNOWLEDGEMENTS}

Authors would like to thank Mr. Franco Mungai, Major of Massarosa, for believing in the research goals and for supporting the project from the institutional point of view. A special thank also to Dr. Luigi Ficacci and Dr. Giulio Ciampoltrini, Authority for Archaeological Heritage, Fine Arts and Landscape in the Provinces of Lucca and Massa Carrara, for allowing to access and survey the Massaciuccoli romana archaeological park. The research has been funded by Fondazione Cassa di Risparmio di Lucca, CARILU. 

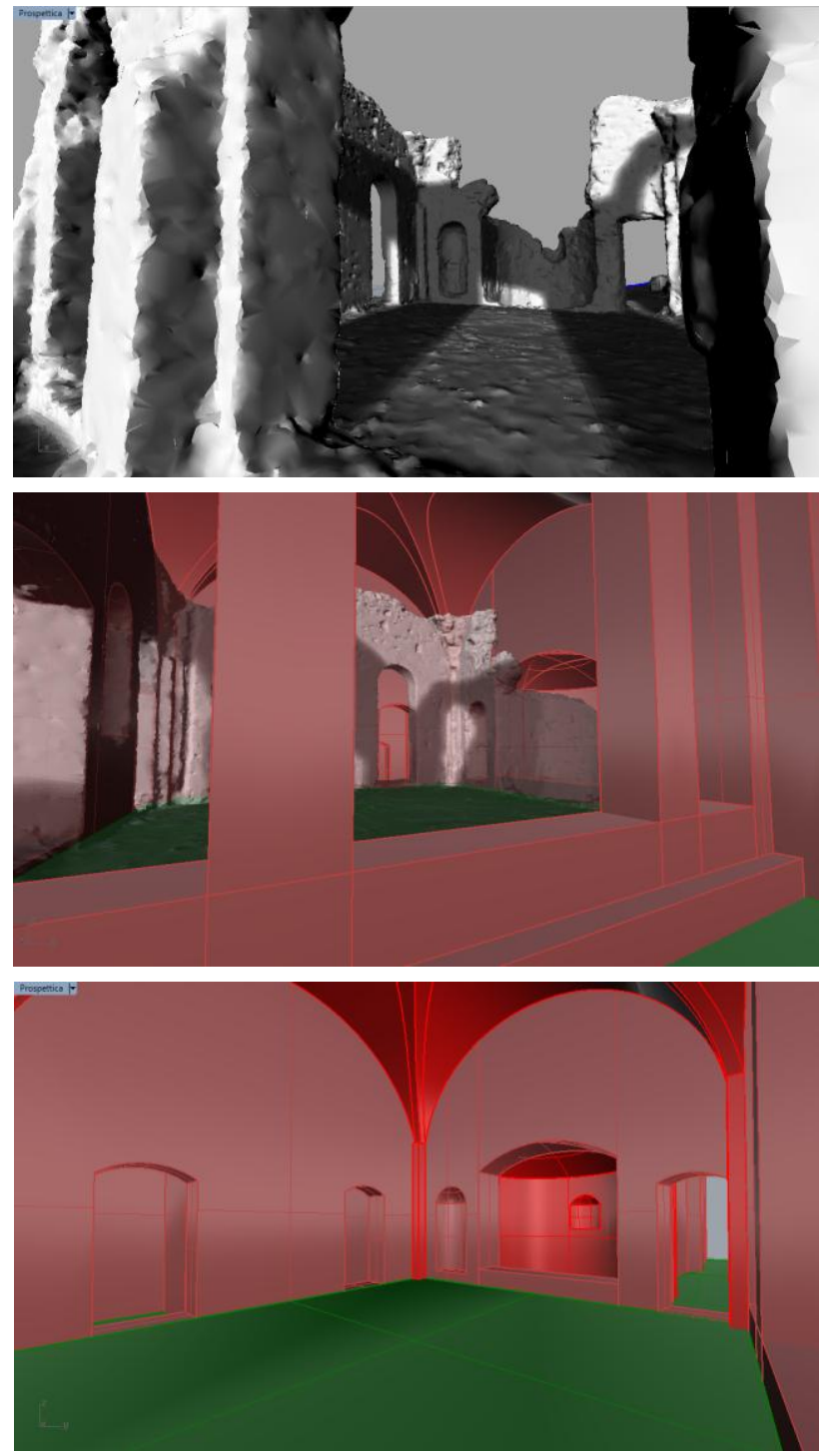

Figure 6. Augmented reality of the thermal area, Massaciuccoli archaeological site. From top to bottom views: 3D model obtained by meshing the laser scanning point cloud (top); modeling the past age by accurately following the geometric information of the current remains (central); virtual 3D reconstruction of a thermal room ( $\mathrm{H}$ and $\mathrm{L}$ in Figure 2) as it appeared in the past (bottom).

\section{REFERENCES}

Arrighi, L., 1963. Le terme romane di Massaciuccoli. Giornale Storico della Lunigiana, 14, pp. 43-46.

Balletti, C., Guerra, F., Scocca, V., Gottardi, C., 2015. 3D integrated methodologies for the documentation and the virtual reconstruction of an archaeological site. The International Archives of Photogrammetry, Remote Sensing and Spatial Information Sciences, 40(5), pp. 215.

Bassani, E., Rosa, E., Sgherri, M., 2013. Cantieri aperti per progetti di fruizione del Cultural Heritage digitalizzato. Storicamente, 9, pp. 3-10.

Besl, P.J., McKay, N.D., 1992. A method for registration of 3-D shapes. IEEE Transactions on Pattern Analysis and Machine Intelligence, 14, pp. 239-256. doi:10.1109/34.121791.
Böhler, W., Hein, G., Marbs, A., 2001. The potential of noncontact close range laser scanners for cultural heritage recording. Proc. of XVIII CIPA Symposium, Postdam, Germany.

Capra, A., Bertacchini, E., Castagnetti, C., Rivola, R., Dubbini, M., 2015. Recent approaches in geodesy and geomatics for structures monitoring. Rendiconti Lincei, 26(1), pp. 53-61. doi: 10.1007/s12210-015-0436-z.

Castagnetti, C., Bertacchini, E., Capra, A., Dubbini, M., 2012. Terrestrial Laser Scanning for Preserving Cultural Heritage: Analysis of Geometric Anomalies for Ancient Structures. Proc. of FIG Working Week, Rome, Italy, pp. 1-13. ISBN 9788790907-98-3.

Chen, Y., Medioni. G., 1992. Object modelling by registration of multiple range images. Image and Vision Computing, 10, pp. 145-155. doi:10.1109/ROBOT.1991.132043.

Ciampoltrini, G., 1994. Gli ozi dei Venulei. Considerazioni sulle terme di Massaciuccoli. Prospettiva, 73-74, pp. 119-130.

Ciampoltrini, G., 1998. La "villa" di Massaciuccoli. Una proposta di lettura. Rassegna di Archeologia, 15, pp. 107-118.

Ciampoltrini, G., 2009. La villa degli 'ozi scomodi' dei Venulei. In: Anichini, F., Paribeni, E. (Editors), Massaciuccoli romana, Felici, Ghezzano (PI), pp. 16-23.

\section{CIL - Corpus Inscriptionum Latinarum, XI, 1433a.}

D'Agnano, F., Balletti, C., Guerra, F., Vernier, P., 2015. Tooteko: a case study of augmented reality for an accessible cultural heritage. Digitization, 3D printing and sensors for an audio-tactile experience. The International Archives of Photogrammetry, Remote Sensing and Spatial Information Sciences, 40(5), pp. 207.

Dubbini, M., Giannini, M., Picone, S., 2016. La cartografia storica della Versilia come strumento di ricostruzione del passato. In: Giannini M., Greco V. (Editors), Visualizzare il paesaggio. Nuove forme di narrazione e rappresentazione dello spazio geografico, BraDypUS Communicating Cultural Heritage, Bologna, pp. 117-154.

Fabiani, F., 2006, “...stratam antiquam quae est per paludes et boscos ...". Viabilità romana tra Pisa e Luni, Edizioni Plus. Pisa University Press, Pisa, pp. 55-61.

Fritz, F., Susperregui, A., Linaza, M.T., 2005. Enhancing Cultural Tourism experiences with Augmented Reality Technologies. $6^{\text {th }}$ International Symposium on Virtual Reality, Archaeology and Cultural Heritage VAST, San Sebastian, Spain.

Giannini, M., 2015. I Romani in Versilia: dinamiche di popolamento e organizzazione del territorio. Orizzonti, XVI, pp. 81-91.

Giannini, M. 2016. Visualizzare un territorio: il progetto VisualVersilia. In: Giannini, M., Greco, V. (Editors), Visualizzare il paesaggio. Nuove forme di narrazione $e$ rappresentazione dello spazio geografico, BraDypUS Communicating Cultural Heritage, Bologna, pp. 81.

Guarnieri, A., Pirotti, F., Vettore, A., 2010. Cultural heritage interactive 3D models on the web: an approach using open 
source and free software. Journal of Cultural Heritage, 11(3), pp. 350-353, doi:10.1016/j.culher.2009.11.011.

Guarnieri, A., Vettore, A., El-Hakim, S., Gonzo, L., 2004. Digital photogrammetry and laser scanning in cultural heritage survey. International Archives of the Photogrammetry, Remote Sensing and Spatial Information Sciences, 35, pp. 154-159.

Meyer, E., Grussenmeyer, P., Perrin, J.O., Durand A., Drap P., 2002. A web information system for the management and the dissemination of Cultural Heritage data. Journal of Cultural Heritage, 3, pp. 325-331.

Minto, A., 1921. Le terme romane di Massaciuccoli. Monumenti antichi, XXVII, pp. 12-15.

National Library of Australia, 2013. Guidelines for the preservation of digital heritage. Information Society Division, United Nations Educational, Scientific and Cultural Organization.

Neubauer, W., Doneus, M., Studnicka, N., Riegl, J., 2005. Combined high resolution laser scanning and photogrammetrical documentation of the pyramids at Giza. CIPA XX International Symposium, Torino, pp. 470-475.

Noh, Z., Sunar, M.S., Pan, Z., 2009. A review on augmented reality for virtual heritage system. International Conference on Technologies for E-Learning and Digital Entertainment, Springer Berlin Heidelberg, pp. 50-61.

Orlandi, M., Zambruno, S., Vazzana, A., 2014. Tecnologia, Beni Culturali e Turismo: i Tour Virtuali (Virtual Tours) come strumento per una corretta comunicazione dei Beni Culturali. Didattica, 2014(34).

Paribeni, E,. 2012. Il sito di Massaciuccoli. In: Anichini, F., Bertelli, E., Ghizzani Marcìa, F., Giannotti, S., Menchini, M., Paribeni, E., Parodi, L. (Editors), Chiedilo all'archeologo. Massaciuccoli romana. Visita guidata a fine scavo, Nuova Cultura Edizioni, Roma, pp. 11-15.

Rivola, R., Castagnetti, C., Bertacchini, E., Casagrande, F., 2016. The geomatic techniques in support of the cultural properties. Digitalization and 3D print of a mosaic in Byzantine technique for documentation and conservation purposes, Archeomatica, VII(1), pp. 34-37.

Targioni Tozzetti, G., 1768-1779. Relazioni di diversi viaggi fatti in diverse parti della Toscana, Vol. I, Stamperia Granducale per Gaetano Cambiagi, Firenze, pp. 452-457.

Tucci, G., Algostino, F., Bucalossi, L., Conti, A., Nobile, A., 2010. Cultural heritage and sustainable valorization in the governorate of tartous with reference to the euromed IV project: the contribution of geomatics. Euro-Mediterranean Conference, Springer Berlin Heidelberg, pp. 399-408.

Tucci, G., Bonora, V., Fiorini, L., Conti, A., 2016. The Florence Baptistery: 3-D Survey as a Knowledge Tool for Historical and Structural Investigations. ISPRS-International Archives of the Photogrammetry, Remote Sensing and Spatial Information Sciences, pp. 977-984.

Tucci, G., Cini, D., Nobile, A., 2011. Effective 3D digitization of archaeological artifacts for interactive virtual museum. Proc. of the $4^{\text {th }}$ ISPRS International Workshop 3D-ARCH, pp. 413420 .

Zhang, Z., 1994. Iterative point matching for registration of free-form curves and surfaces. International Journal of Computer Vision, 13, pp. 119-152. doi:10.1007/BF01427149.

\section{AUTHORS' INDIVIDUAL CONTRIBUTION}

CASTAGNETTI C.: manuscript design, coordination and writing; 3D survey execution. Corresponding author.

GIANNINI M.: historical documentation on the case study, writing section 2 and fund raising for the project.

RIVOLA R.: 3D survey design, execution and data processing. 